\title{
Decorative Flower Pots of Batak Toba and Malay as a Tourist Souvenir that is Used as an Interior Element
}

\author{
$1^{\text {st }}$ Mesra $^{1}, 2^{\text {nd }}$ Gamal Kartono ${ }^{2}, 3^{\text {rd }}$ Anam Ibrahim $^{3}$ \\ \{mesra@unimed.ac.id ${ }^{1}$, gmalkart@gmail.com² ${ }^{2}$ jamurayu074@gmail.com ${ }^{3}$ \} \\ Department of Fine Arts, Faculty of Languages and Arts, Universitas Negeri Medan, Indonesia ${ }^{1,2,3}$
}

\begin{abstract}
The traditional art of North Sumatra has begun to disappear and the efforts to preserve it has not shown serious steps. Therefore, it is necessary to take measures aimed at preserving this traditional culture. One of the steps that can be taken is researchers conducted a revitalization of ornaments with digitalization techniques. The change from the manual method (drawn and carved) was then developed into corel draw program and printed on albatross media. Printed images and accompanying information can be pasted to decorate decorative items. In this study, the ornaments applied were from Batak Toba and Malay ethnic. The application of ornaments to decorate decorative flower pot is also functioned as an interior element. It is hoped that this method will be quite effective in re-socializing the traditional ornaments of North Sumatra to the younger generation.
\end{abstract}

Keywords: Traditional ornaments, digitization, souvenirs, interior.

\section{Introduction}

North Sumatra traditional ornaments are usually applied to the walls of traditional houses, residential houses, government offices, traditional clothes and objects that are used as symbols in customs. People believe that the application of ornaments gives strength, protection, and prosperity to humans. Therefore, traditional ornaments are seen as visualizations of sacred symbols.

At present, the younger generation no longer continues the history of North Sumatra traditional ornaments, and no longer uses them as a guide in life. Therefore, traditional ornaments are gradually becoming extinct. These ornaments should be preserved by incorporating them into learning in primary and secondary schools as local content.

Batak Toba ethnicity and Malay ethnicity are seen as samples of North Sumatran society that represent the nominations of Christianity and Islam. Even though they have different religious beliefs, these people live side by side in harmony, maintain unity and peace. One of the media that unifies the community is traditional ornaments. The shape, color, and meaning of the ornament are the result of the agreement of the supporting community, where each other is oriented towards maintaining harmony in living together.

The variety of shapes and colors of traditional ornaments is an inspiration for art students today. This can be developed in the creation of works of art, as well as can arouse the attention of the wider community to recognize them again. The color of the Batak Toba ethnic ornaments can represent the color of the ornaments of other Batak ethnicities. The colors are red, white and black. While the Malays use different colors from all the Batak ethnic groups, 
namely green and yellow. From the two green and yellow colors, only lighter and darker intensity variations are made, so that there are dark and light green, dark and light yellow.

By utilizing modern technology (computers) variations in the shape and color of ornaments can be developed to make them look more attractive. However, of course to maintain the original characteristics of these changes, while maintaining the original shape and color. The use of computers is prioritized in documenting ornaments digitally, and to facilitate reproduction with the same quality standards.

The development of new products with local characteristics is important to provide variety between regions and attract tourists to visit North Sumatra. The North Sumatra Tourism Office strongly encourages the public to present local souvenir products. Former Minister of Tourism and Creative Economy, Wishnutama Kusubandio explained that the general focus of the tourism economic recovery will be in 2021. The future programs will mainly focus on the development of five priority destinations, namely Lake Toba, Borobudur, Mandalika, Labuan Bajo, and Likupang.

On this occasion the researchers designed a souvenir product that answers the needs of today's society, namely a decorative flower pots that is characterized by the Batak Toba and the Melayu Tribe. In the past year, there has been a tendency for Indonesian people to show a hobby of collecting various types of taro flowers. The taro flower is generally suitable for display in a protected place, such as on the terrace or lobby of the building. Therefore, this decorative flower pots product is also designed as an interior element in hotel buildings, offices, homes, and others. The specialty of this product design is that it is easy to disassemble, lightweight, and packaged in a cardboard box for easy portability. The beauty of this decorative flower pots product, supports each other with the beauty of the flowers stored in it, and together gives beauty to the interior of the building.

This decorative flower pots product with traditional Batak Toba and Malay ethnic ornaments is expected to add to the beauty of the interior of hotels, offices, houses and other buildings. The contrasting variations in the shape and color of the Batak Toba and Malay Tribe ornaments are expected to liven up the dynamic atmosphere in the building space.

Another benefit of this product is also as a medium for socializing traditional Batak Toba and Malay ornaments to the younger generation. On the side of the ornament is written the name and description of the ornament so that the younger generation can get to know it again. In this way, it is hoped that it will avoid extinction. For tourists who come from other regions and abroad can add knowledge, about the traditional culture of North Sumatra.

The formulations of the problem are a) How much tourists are interested in having Batak Toba and Malay decorative flower pots as souvenirs? b) To what extent can Batak Toba and Malay decorative flower pots add beauty to the interior of the building? c) To what extent is the effectiveness of the Batak Toba and Malay decorative flower pot products as a medium for socializing traditional ornaments to the younger generation?

The research objectives are a) Want to know the amount of interest of tourists to have souvenirs displaying flower pots with Batak Toba and Malay ornaments. b) Want to know the level of beauty of the interior of the building, which is enriched by displays of Batak Toba and Malay decorative flower pots. c) Want to know the success rate of socialization of Batak Toba and Malay ornaments to the younger generation through its application to decorative flower pot products, supported by writing names and descriptions of the ornaments.

The research contributions are a) In the development of science and technology where new products can be created to meet the needs of the community. b) Dissemination of knowledge about the history of the traditional culture of Batak Toba and Malay ornaments to the younger generation, to prevent extinction, and to inspire the creation of new works of art. 
c) Enriching the repertoire of interior design by creating new elements in the form of decorative flower pots with local ornaments. d) This Word document can be used as a template for papers to be published in EAI Core Proceedings. Follow the text for further instructions on text formating, tables, figures, citations and references.

\section{Theory}

\subsection{Decorative Flower Pots}

Decorative flower pots are containers for placing (displaying) small flower pots to provide beauty in their arrangement.There are many variations of decorative flower pots, in terms of shape, size, and type of material used. The forms of decorative flower pots include shelves, barrels or boxes, and rope hangers. The materials used include iron, wood, bamboo, rattan, and rope, for an example see Figure 1 and Figure 2.

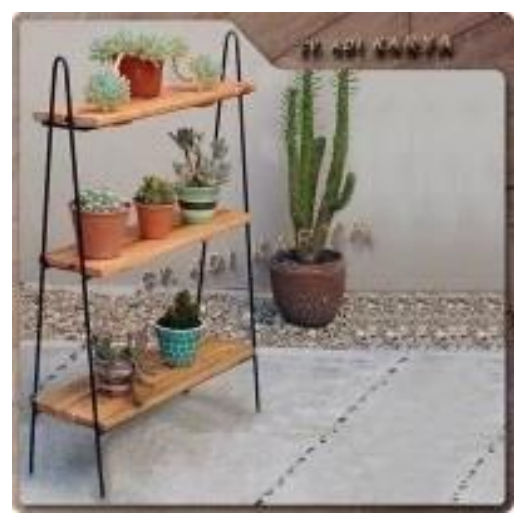

Fig. 1. Decorative flower pots from iron and wood.

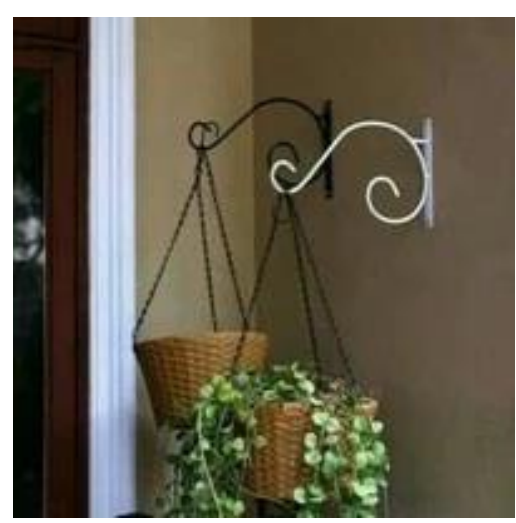

Fig. 2. Decorative flower pots from rattan and rope. 
In general, the display of flower pots as a planting container. Only a small part of the flower pot display covers the pot (only the flowers can be seen). There are two things to note in the flower pot display method. First, flower pots made of plastic (recycled) show low quality. Flowers planted in pots are sometimes expensive. Therefore, several things happened between the luxury of flowers and cheap pots.

Second, a flower pot display designed to cover the pot, so that only the flowers are visible. The displays in question are generally in the form of boxes or barrels. The flower pot display in the form of a box is deliberately designed to look beautiful or luxurious, because it also works as an interior decoration. This is a solution, so that the flower pot (as a planting container) is no longer visible.

Why are flower pots made of plastic? The main considerations are in terms of practicality, namely light, durable, and cheap in price. Light is needed from a flower pot, because flower pots are often moved around to get a beautiful arrangement. Makes it easier to replace the soil when the humus has run out or the roots of the plant are too dense in the pot. Durable, is the nature of plastic that is not easily broken, strong, and water resistant (not easily weathered). Flowers are expected to grow for a long time as decoration, so plastic pots can meet these needs. Even though the soil has been changed several times, the pot is still good to use. The price of flower pots is cheap because of low-quality materials, mass production from the industry, so the price is more affordable for consumers.

Maybe the beauty of flower pots is often overlooked by some people, because their function is only as a planting container filled with soil. But of course this is not the case for people who have a high sense of beauty, especially if flower pots are used as an interior element. The solution taken to meet these needs is to first buy a quality flower pot (for example, made of porcelain ceramics, made of glass, or made of metal). Of course you need to be very careful, because it breaks easily and is quite heavy. Second, buy displays in the form of boxes or barrels, where to put flower pots in them. The display is indeed designed in such a way as an interior element. The flower pot that is inserted into it will not be seen, only the flowers can be seen. Thus, there is no need to buy an expensive and easily broken flower pot, just a cheap plastic flower pot (because it will be covered by the flower pot display), but the beauty of the flower pot display is visible.

\subsection{Souvenir Product Requirements}

Generally, souvenir products are made in a portable form (lightweight, easy to carry and move) so that they do not bother consumers. Generally, tourists often see the regional characteristics of souvenir products, the neatness of the shape, and the quality of the materials. The principles of souvenir design include original, simple, functional, strong, safe, pretty/funny/elegant, modern/historical, geometry (....). Departing from this, on this occasion the researchers tried to develop unique, simple, functional, durable, and aesthetic souvenir products characterized by the local area.

Simple and portable, this product is realized in a form that is disassembly and then packaged in a cardboard box that can be carried (lightweight). The decorative flower pots that the researchers present here are not only strong for displaying flower pots, but also their luxurious looks, which will be presented as elements of the interior of the building.

This souvenir is deliberately designed not only as a memory when it comes to a tourist destination, but more than that to create an atmosphere of beauty at home. Maybe we are used to souvenirs that are only miniature (eg miniature Eiffel tower, Boroudur temple, etc.), but cannot be functional. So on this occasion created souvenirs that are immediately functional. 
The strategy to achieve this goal is to use the dismantling technique. Decorative flower pots generally have a large and heavy size, so they are rarely used as souvenirs. Therefore, the researchers initiated it using lightweight materials, disassembled and packaged in a cardboard that is easy to carry. For comparison, this product can be compared to a plastic cupboard. Maybe almost evenly people know about the plastic cabinets that we buy in the market, in cardboard packaging that is stretched. Then after arriving home, it is assembled into a fairly large wardrobe (eg. $85 \times 150 \times 45 \mathrm{~cm})$

The decorative flower pots designed by the researcher can cover this simple and cheap impression, because it presents a unique shape, characteristic of the local area, and is specially designed as an interior element. It is hoped that this product will become an interior element innovation in the future.

\subsection{Traditional Ornaments as decoration of modern products}

The general understanding of ornament is decoration applied to functional objects such as building walls, furniture objects, clothing and others. Ornaments can be in the form of a collection of motifs that are combined in a single unit to become a decoration. According to the author [1] explains:

Ornament is a component of an artistic product that is added or intentionally made for the purpose of decoration. In addition to his implicit duties concerning aspects of beauty, for example, to add to the beauty of an item so that it is better and more attractive, the consequences also affect the appreciation in terms of material/financial aspects. In addition, in ornaments, which are often found symbolic values or certain purposes that have to do with the view of life (views of life) of humans or their loving community, so that objects that are subject to an ornament will have a deeper meaning, accompanied by certain expectations as well. [1]

The existence of ornaments is to satisfy the sense of human beauty in the present and in the future [1]. Meanwhile, starting from prehistoric times in Indonesia, until today the existence of traditional ornaments is always needed in human life. The application of ornaments can be done by chiseling/carving, drawing/painting, weaving/stamping, and so on. The main purpose is to give the value of beauty, and the other purpose is to convey messages or advice, and have the values of magical power.

Traditional ornament is a form of decoration that has certain criteria or special provisions, both in terms of shape, color, place of placement, and the meaning or messages conveyed. These special provisions are the result of an agreement from a group of people who live together or a certain ethnic community. "Ornaments are decorations in the form of patterns and have cultural values" [2]. What is meant by cultural values is the existence of moral messages conveyed through these ornaments. Then there are also religious values it contains based on the beliefs of the ethnic communities that support it. He further explained that a review of traditional ornaments found in North Sumatra in general can be seen based on the form of images, in the form of human shapes, animal shapes, giant shapes, plant shapes, geometric shapes, and natural or cosmic shapes.

The use of traditional ornaments as decoration of modern objects is one of the efforts to revitalize the past culture so that it will still exist in the future. Then the traditional ornaments have different patterns in each region of the archipelago, so that it will be an attraction for tourists to visit these areas. A habit of tourists is to bring home mementos from the areas they have visited. The mementos that are expected are those that are characteristic of the area itself, which are unique, beautiful, and long-lasting. 
The application of ornaments on display objects is very meaningful so that it becomes a source of pride for the creators and observers of these products. This is also displayed on functional objects (crafts) in addition to being used as a practical function as well as a decorative function. More than that, functional objects can also switch functions to be merely decoration or display, depending on the creator and user, an approach with the term "art craft" is used [3].

\subsection{Application of Displays as Interior Elements}

The interior components include; floors, walls, ceilings (ceilings), windows, doors, furniture, and accessories [4]. One of these components, namely accessories, that the addition of accessories can add visual richness and taste to an interior arrangement [5]. These accessories can be in the form of useful objects, elements, and architectural accessories and art objects and plants.

Based on the quote above, this study tries to realize one of the components of interior accessories, namely decorative flower pots. The display of flower pots is clearly an art object that has an applied function. The application of indoor flower pot displays (loby) gives a refreshing and visually pleasing feeling because of the fresh live flowers plus brightly colored ornaments on the outside of the display box.

\subsection{Digital Ornament Processing}

Information digitization is the process of converting various information, news, or news from an analog format to a digital format so that it is easier to produce, store, manage and distribute. For many years since our ancestors, the documentation of traditional ornaments is usually in the form of books and photographs. In addition, the documentation of the ornament itself is carved on the walls of the building, woven on clothes and glued to traditional equipment. The difficulties faced by the community, especially when they want to reproduce or apply to other places, must be redesigned manually. This will take more time and also have the potential to be distorted than the original shape. Therefore, digital documentation is a very good solution in dealing with this problem.

Along with advances in technology and science, the traditional simple or manual methods have begun to be replaced with technological aids. People have used computer tools to design designs and apply print techniques. Thus there is also a change in the application of these ornaments in the desired areas.

At present, all forms of traditional ornaments can be traced through digital media, so that the history, shape, and color will be well documented. Then it can also be obtained the convenience of reproducing (reproducing) the form easily whenever desired. In addition, the younger generation can also use the digital documentation as an inspiration to create new creations. Traditional ornaments are the basis for creating innovative art forms, or as a means of revitalization.

Changes in the creation of ornaments with the digital print method will not replace the chiseling technique of the past, because the prints are not suitable for application to the walls of buildings made of cement, or wood. Currently, many people have printed traditional ornaments on plastic material in the form of banners. The disadvantages of plastic materials are that they do not last long, are easily torn, and the color fades quickly. This means that the revitalization of traditional ornaments will not completely produce products exactly in the past, but will adapt to the conditions that exist in the present. 
Utilization of digital techniques for reproduction is very advantageous in terms of speed and accuracy. The print method can duplicate quickly and have the same shape, size, and color. Digitization efforts also need to be adjusted to the target where it will be applied. In addition, digitalization products also have various limitations, so it is necessary to study their benefits for the community.

\subsection{Digital printing}

Digital printing is a printing method of digital-based images, which are usually in the form of files, which can then be directly printed on various media instantly and quickly. Digital printing is a modern method that involves digital techniques in designing towards physical materials or media [6].

The times have also made digital printing possible to print media from semi-plastic materials for outdoor use, such as banners, billboards, banners and so on. The development of the digital printing world provides many advantages for business owners, because promotional media can be made as attractive as possible at a lower cost.

In this study, digital printing is very useful for producing attractive ornamental forms, with very precise size accuracy, while displaying harmonious and long-lasting colors. There are several types of digital print media materials, namely vinyl frontlite banner, vinyl backlite banner, vinyl sticker, one way sticker, albatross, luster, canvas, pvc, glossy paper, and sticker. These materials have different textures and functions depending on the needs of consumers. There are types of materials that are usually used for outdoor, and there are also materials that are specifically for indoor. Materials that are often used indoors cannot be used for outdoor, but materials commonly used for outdoor can be used as indoor. The material used in this research is albatross which is for indoor. Albatross is similar to thin plastic which is matte (not shiny) and produces elegant, more subdued, dim, luxurious and exclusive printed colors. Doff prints are more durable and durable even though they are often held and do not leave fingerprints.

\subsection{Development Style}

The model used in this study is Research and Development by Borg and Gall (1983), namely the research method used to produce certain products, and to test the effectiveness of these products [7]. Research and development was carried out on traditional ornate flower pot display products of Toba Batak and North Sumatran Malays.

Development Research is an attempt to develop an effective product for school use, and not to test theory. Meanwhile, the authors [7] define development research as follows:

Educational Research and development $(\mathrm{R} \& \mathrm{D})$ is a process used to develop and validate educational products. The steps of this process are usually referred to as the R \& D cycle, which consists of studying research findings pertinent to the product to be developed, developing the products based on these findings, field testing it in the setting where it will be used eventually, and revising it to correct the deficiencies found in the filed-testing stage. In more rigorous programs of $\mathrm{R} \& \mathrm{D}$, this cycle is repeated until the field-test data indicates that the product meets its behaviorally defined objectives. [7]

Research and development (R\&D) is the process used to develop and validate educational products. The steps of this process are usually referred to as the R\&D cycle, which consists of studying the research findings related to the product to be developed, developing the product based on these findings, the testing area in the setting where it will be used eventually, and 
revising it to correct deficiencies found in the stage of submitting the test. In a more stringent program of $\mathrm{R} \& \mathrm{D}$, this cycle is repeated until the test-data field shows that the product meets the defined behavioral objectives. Development research as a systematic study of the design, development and evaluation of programs, processes and learning products that must meet the criteria of validity, practicality, and effectiveness [8]. While the criterion of "can show added value" in addition to the three criteria [9].

Development research is carried out with the following strategies and steps: (1) initial assessment (define), (2) design, (3) realization (construction), (4) Testing, Evaluation, and (5) Revision.

\subsection{Research and Technology Roadmap}

To further clarify the research plan and program in detail, see the research roadmap in Figure 3.

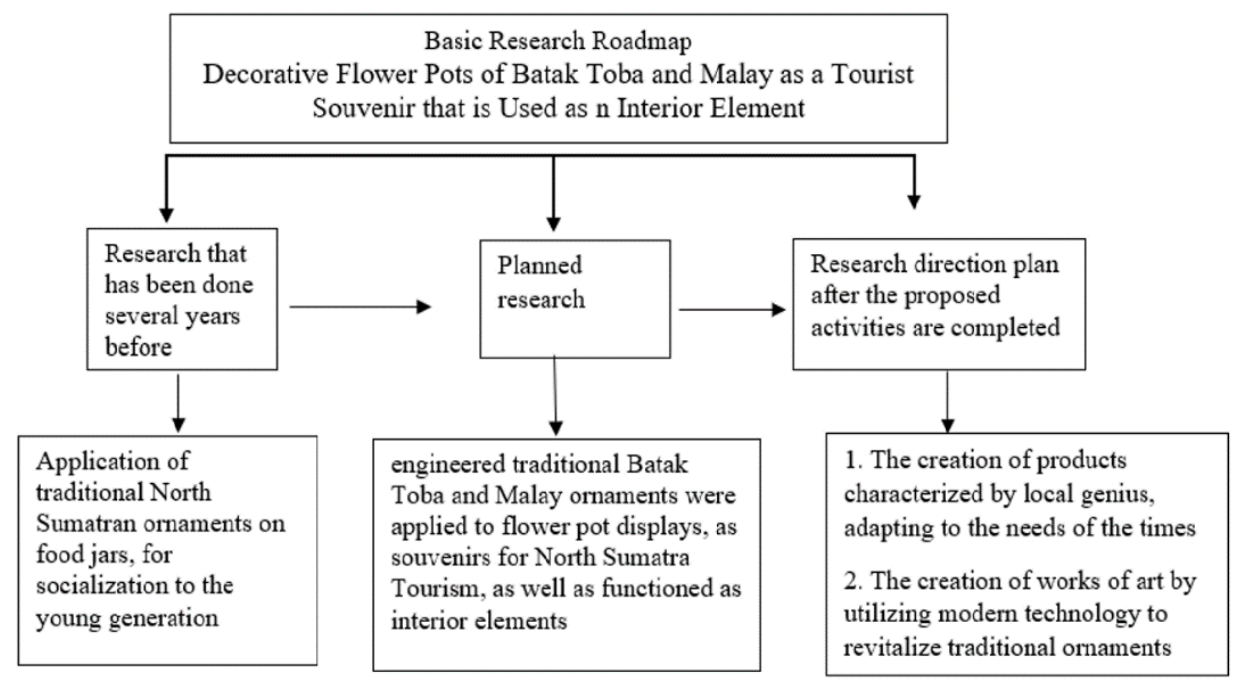

Fig. 3. Basic Research Roadmap. 


\section{Method}

The flowchart of the research implementation in detail is described in Figure 4.

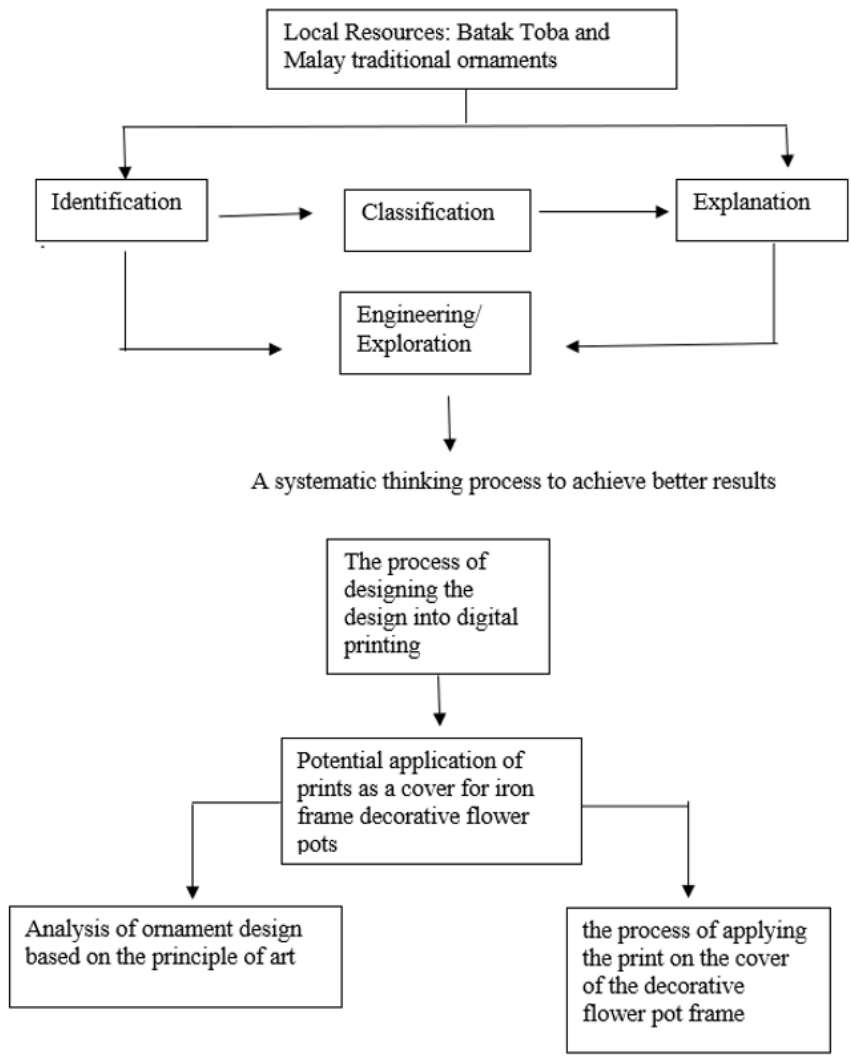

Fig. 4. Research Flowchart.

The technical steps for carrying out the research can be described as follows: There are two technical working groups used in producing ornamental flower pot display products of Batak Toba and Malay tribes. Group A is technical related to the creation of ornaments as an outer decoration of flower pots. Group B is the technical creation of decorative flower pots frames. Furthermore, the technical steps for each group will be described as follows:

The technical procurement of ornaments are 1) Collecting data on traditional forms of Batak Toba and Malay ornaments. The method is by reviewing the literature (through documentation books) and through web browsing (internet). 2) Choose the forms of ornaments that will be applied as flower pot decorations. 3) Assess (consider) the beauty of the ornament and its layout as a decoration on the outside of the decorative flower pots. 4) Designing the shape of the ornament through a computer program in accordance with the method of making digital printing, taking into account the size of its application on decorative flower pots. 5) Produce/print as many applications as needed on decorative flower pots. 6) Paste the print on the plywood sheet which will later cover the outer side of the decorative flower pots. 7) Apply 
the cutting sticker of the traditional North Sumatran ornament on thedecorative flower pots, taking into account the beauty of the final shape of the flower pots.

The technical procurement of decorative flower pots frames are 1) Make a design drawing of a decorative flower pots frame. 2) Choosing materials and considering various ease of production (the material is made of light iron). 3) Make a decorative flower pots frame with a welding technique based on the design drawing. 4) Finishing by painting the decorative flower pot frame.

There are 18 forms of Batak Toba ornaments that can be developed in digital printing, and 15 forms of Malay ornaments, which can be arranged in such a way as to achieve an aesthetically pleasing product presentation. For example, the following ornaments on Figure 5 can be displayed, which will later be processed using a computer program to decorate the outside of the decorative flower pots.
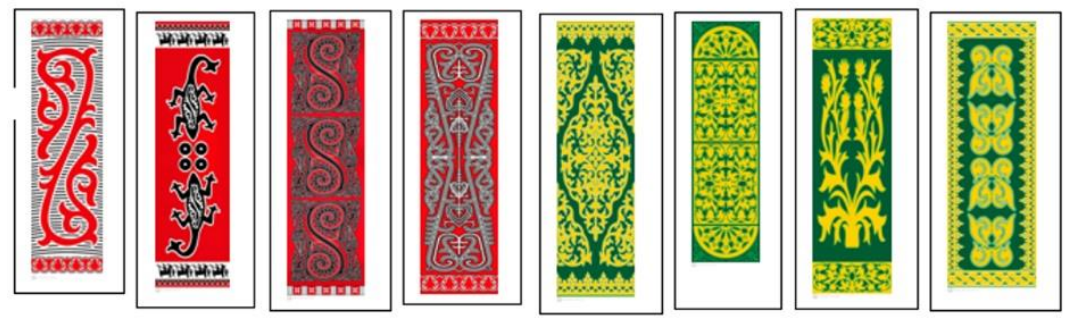

Fig. 5. Ornaments of Batak Toba and Malay ethnic.

The examples of ornaments above are only a small part of the Batak Toba ornaments and the Malays have not been selected as research samples, because the selection will be carried out in a research team meeting at the stage of the selection process.

Based on the potential form of ornaments and the shape of the decorative flower pots, an engineering application was made with several alternatives, including 2 following Figures, Figure 6 and Figure 7.

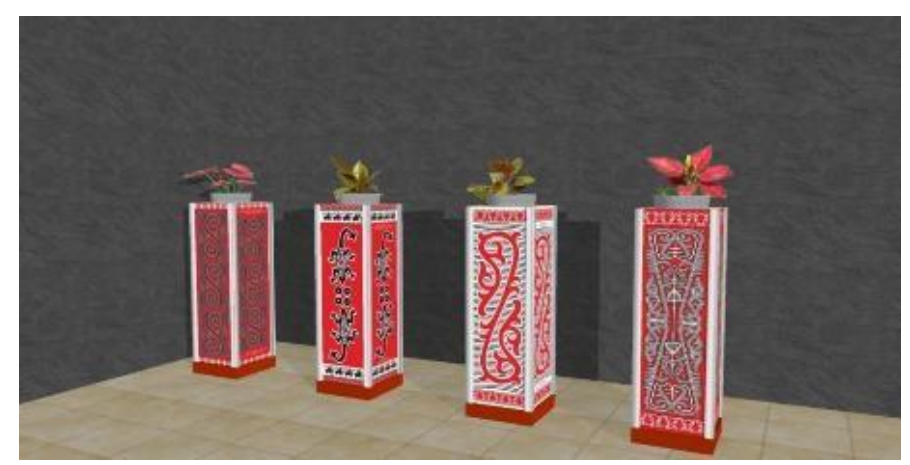

Fig. 6. Engineering design of Toba Batak ornament. 


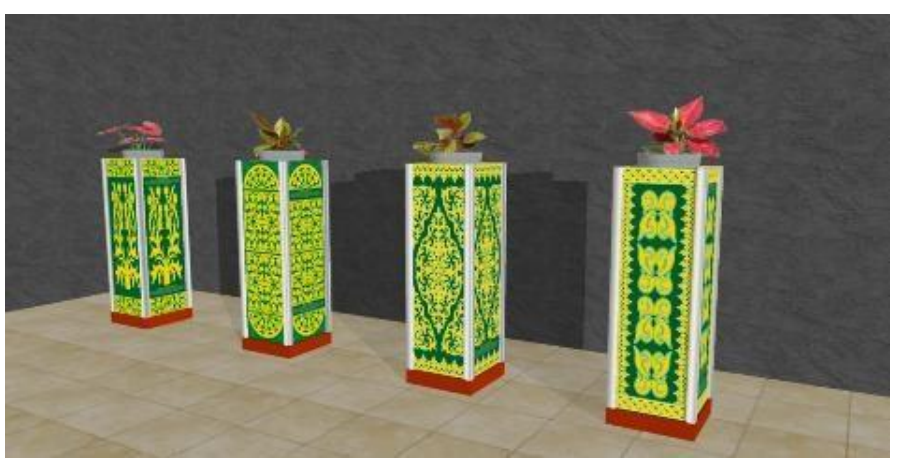

Fig. 7. Engineering design of Malay ornament.

The choice of products can be developed into three height sizes, namely $50 \mathrm{~cm}, 75 \mathrm{~cm}$, and $90 \mathrm{~cm}$. Consumers can buy according to their taste either one by one, or as a set (3 different sizes). This alternative is made so that consumers can adjust to their purchasing power.

\section{Results and Discussion}

After conducting studies on the shape of the ornament design that will be selected, then conducting experiments on modifying the shape, size, and color, taking into account the harmony (aesthetics) of the ornament, and the means of application (i.e. flower pot display) where there are various shapes and sizes, then obtained ornaments that can be displayed as new creations for revitalization facilities. The beauty of an ornament that is displayed, of course, is very subjective in nature, where the tastes of the designer and the observer are not necessarily the same. However, the application of the basic concepts of composition in general, will be able to meet the target of beauty in general.

\subsection{Construction engineering design}

Based on the potential shape of the ornament and the shape of the flower pot display that you want, an engineering application is made with several alternatives, including the following: Product options can be developed in three height sizes, namely $50 \mathrm{~cm}, 75 \mathrm{~cm}$, and $90 \mathrm{~cm}$. Consumers can buy according to their taste either one by one, or as a set (3 pieces of different sizes). This alternative is made so that consumers can adjust to their purchasing power. Technological engineering of disassembling flower pots for display can be seen in Figure 8 and the installation of the outer side cover of the flower pot display frame can be seen in Figure 9. 


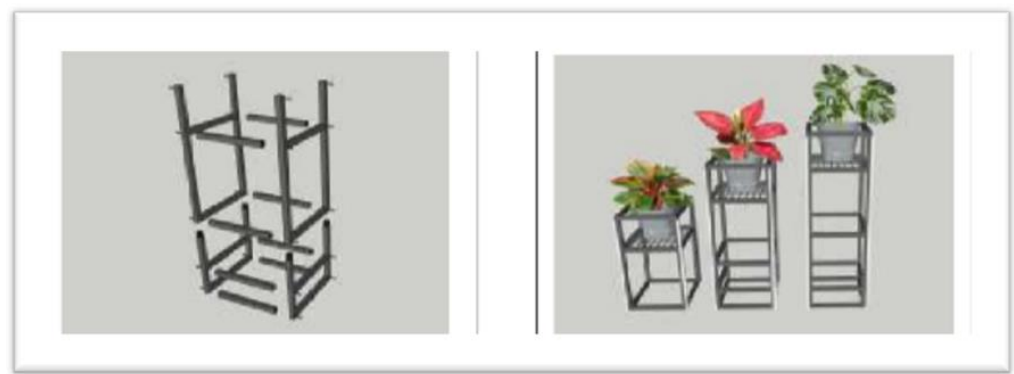

Fig. 8. Flower pot Display Construction Design.

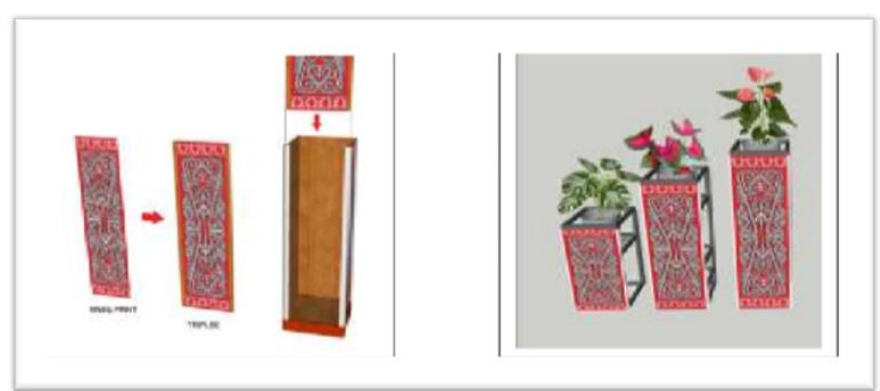

Fig. 9. Ornate Frame Cover Application Design.

\subsection{Achievement progress}

Making an iron frame for displaying flower pots by involving a welding workshop business guided by researchers as planned. After finishing welding and then assembled as shown in Figure 10 below:

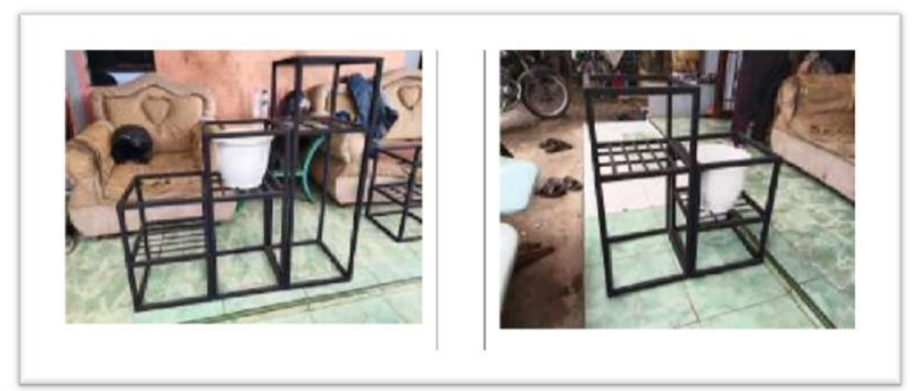

Fig. 10. Flowerpot Display Frame Assembly.

Design development is carried out using laptop media using the Corel Draw application. Then proceed with the digital print process, involving printing services. The print on the albatross material is then cut into pieces according to the size of the side of the iron frame. The printed material is glued to the plywood side cover of the iron frame as shown in Figure 11 below. 


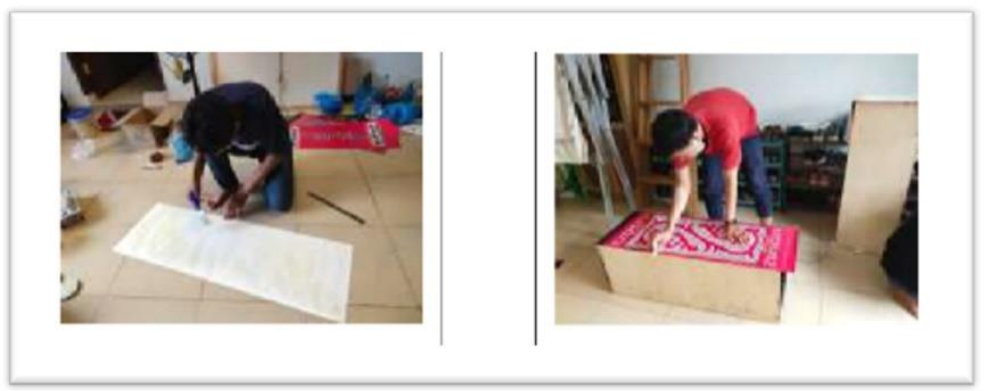

Fig. 11. Application of Ornament Print Results on Plywood.

After completing the installation of the iron frame side cover, the flower pot can be inserted into the display area and can be arranged in such a way as the interior of the room. The final result of the flower pot display can be seen in Figure 12 below.

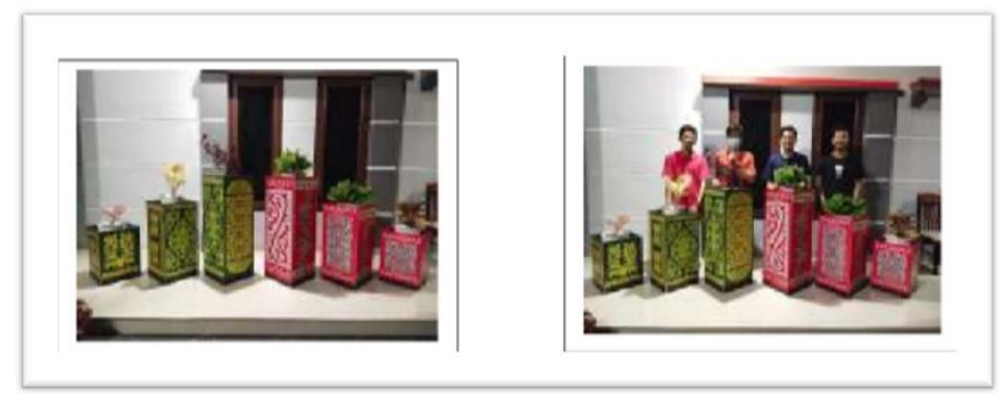

Fig. 12. The final result of the flower pot display.

\section{Conclusion}

The application of traditional ornaments to decorate today's products will still attract attention, and have a beautiful or artistic appearance. Of course, the business uses modern technology as a means of modification, as well as materials that are suitable for today. Reviving the art style of the past that is packaged in a modern way will give an antique, unique impression, and encourage the younger generation to relearn the arts and culture of the past. This revitalization effort is useful for preserving traditional art products so that they do not become extinct. The product of this research can be used as a model in its development as a source of livelihood for the community. The manufacture of products will become a new field of employment, then the sale will also open a new product trading business.

\section{References}

[1] Gustami SP. Nukilan Seni Ornamen Indonesia. Yogyakarta: STSRI ASRI; 1980.

[2] Sirait B. Pengumpulan dan Dokumentasi Ornamen Tradisional di Sumatera Utara. Medan: IKIP Medan Publisher; 1980.

[3] Eskak E. Potensi Seni Kriya Istimewa dalam Pameran Negari Ngayogyakarta Hadiningrat 2012. CORAK J Seni Kriya. 2013; 1(2):133-142. 
[4] Wicaksono A, Tisnawati E. Teori Interior. Jakarta: Griaya Kreasi; 2014.

[5] Riadi M. Desain Interior (Elemen, Komponen, Aspek, Prinsip dan Model). Available from: https://www.kajianpustaka.com/2020/07/desain-interior.html [Accessed $10^{\text {th }}$ Juny 2021].

[6] Pryana I. Pengertian Digital Printing \& Kelebihannya untuk Percetakan. Jakarta: Solusiprinting; 2020.

[7] Borg WR, Gall MD. Educational Research, An Introduction. New York: Longman Inc; 1983.

[8] Seals BB, Richey R. Teknologi Pembelajaran: Defenisi dan Kwasannya. Jakarta: IPTPI LPTK UNJ Publisher; 1994.

[9] Plomp T. Educational Design Research: An Introduction. Netherlands: Enschede; 2013. 